\title{
Expeditious, mechanochemical synthesis of BODIPY dyes
}

\author{
Laramie P. Jameson and Sergei V. Dzyuba ${ }^{*}$
}

\author{
Letter \\ Address: \\ Department of Chemistry, Texas Christian University, Fort Worth, TX \\ 76129, USA \\ Email: \\ Sergei V. Dzyuba* - s.dzyuba@tcu.edu \\ * Corresponding author \\ $\S$ Tel.: +1-817-257-6218; fax: +1-817-257-5851 \\ Keywords: \\ BODIPY; condensation; fluorescent dye; mechanochemistry; \\ solvent-free
}

Beilstein J. Org. Chem. 2013, 9, 786-790.

doi:10.3762/bjoc.9.89

Received: 08 February 2013

Accepted: 29 March 2013

Published: 23 April 2013

Associate Editor: T. P. Yoon

(C) 2013 Jameson and Dzyuba; licensee Beilstein-Institut. License and terms: see end of document.

\begin{abstract} require reaction times of several hours to days.

\section{Introduction}

BODIPY dyes are fluorescent organic molecules, which have received a lot of attention in recent years due to their favorable chemical and physical characteristics, including high quantum yields and tunable fluorescent properties as well as high thermal and chemical stabilities [1-3]. As such, BODIPY and their derivatives have found widespread utility in a variety of different applications including biological [4-7] and lightharvesting systems [8-11].
\end{abstract}

BODIPY dyes have been synthesized under solvent-free or essentially solvent-free conditions, within about 5 minutes in an opento-air setup by using a pestle and mortar, with yields that are comparable to those obtained via traditional routes that typically

Despite wide applicability, the synthetic access to BODIPY dyes is neither facile nor efficient nor expeditious. The synthesis of BODIPY dyes is typically achieved by one of two different one-pot procedures (Scheme 1) [1,2]: (a) Lewis acid (usually trifluoroacetic acid, TFA) catalyzed condensation between a 2-substituted pyrrole and an aldehyde, followed by oxidation with DDQ or $p$-chloranil, and subsequent treatment with base ( $\mathrm{Et}_{3} \mathrm{~N}$ or Hunig's base are typically used) and $\mathrm{BF}_{3} \cdot \mathrm{OEt}_{2}$; (b) pyrrole condensation with an acid chloride and subsequent treatment with base (also usually $\mathrm{Et}_{3} \mathrm{~N}$ or Hunig's base as in procedure a) followed by treatment with $\mathrm{BF}_{3} \cdot \mathrm{OEt}_{2}$.

While the synthesis of BODIPY dyes from the corresponding acid chloride (Scheme 1b) is frequently reported to give somewhat better yields (albeit reaction times of several days are often encountered), the structural diversity of commercially available acid chlorides is limited, and they must be prepared from the corresponding acid. Furthermore, the sensitivity of acid chlorides to moisture imposes additional constrains. 


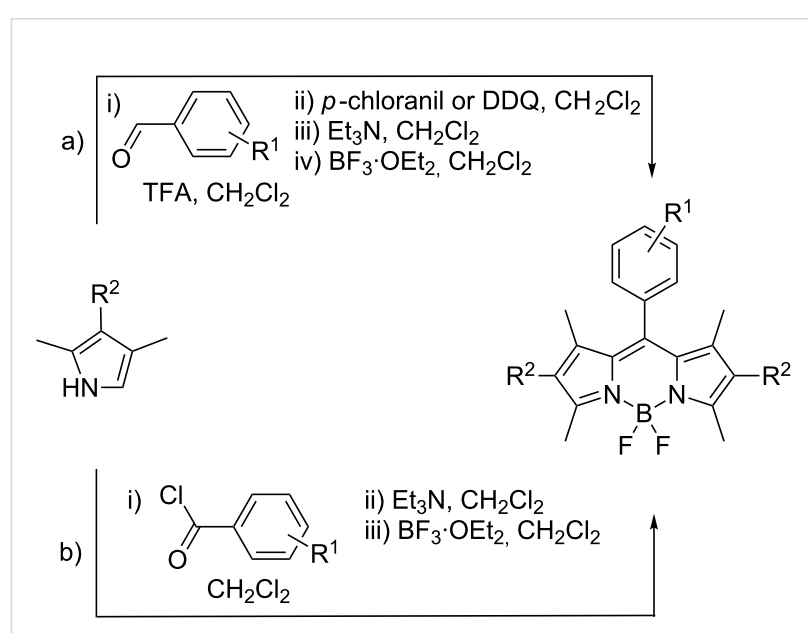

Scheme 1: Literature preparations of symmetric, meso-substituted BODIPY dyes.

Accordingly, the condensation of pyrroles with aldehydes (Scheme 1a) is the more commonly utilized synthetic approach $[1,2]$. Notably, both approaches are carried out under an inert atmosphere. Overall, based on literature accounts, BODIPY synthesis requires long reaction times (several hours to several days) and isolation of the dyes is performed by chromatography, with poor to moderate $(10-50 \%)$ yields.

In this light, a more expedient synthesis of the BODIPY dyes is desired. Toward this end, we reasoned that the condensation step between the 2-substituted pyrroles and aldehydes (or acid chlorides) should be more facile at higher concentrations and probably most efficient under neat conditions. All the subsequent steps should also, in principle, benefit from high concentrations.

\section{Results and Discussion}

As a trial reaction, we attempted a mechanochemical synthesis of BODIPY dye 1 [12] with commonly used reagents. The condensation of 2,4-dimethylpyrrole and 4-nitrobenzaldehyde was performed with grinding by using a simple mortar and pestle, followed by the addition of a few drops of TFA (complete consumption of the aldehyde was confirmed by TLC) and oxidation with $p$-chloranil. The reaction mixture was subsequently treated with $\mathrm{Et}_{3} \mathrm{~N}$ and $\mathrm{BF}_{3} \cdot \mathrm{OEt}_{2}$ to afford BODIPY dye $\mathbf{1}$ (Scheme 2). All reagents were added sequentially with grinding in ca. 5 minutes. Each step was accompanied by a color change. The desired product was isolated in $29 \%$ yield, which was comparable to those reported in literature protocols, $24-40 \%$ (Supporting Information File 1, Table S1), but in a substantially shorter reaction time. The reported reaction times for the synthesis of dye 1 range from 5 hours to ca. 12 hours (or overnight).

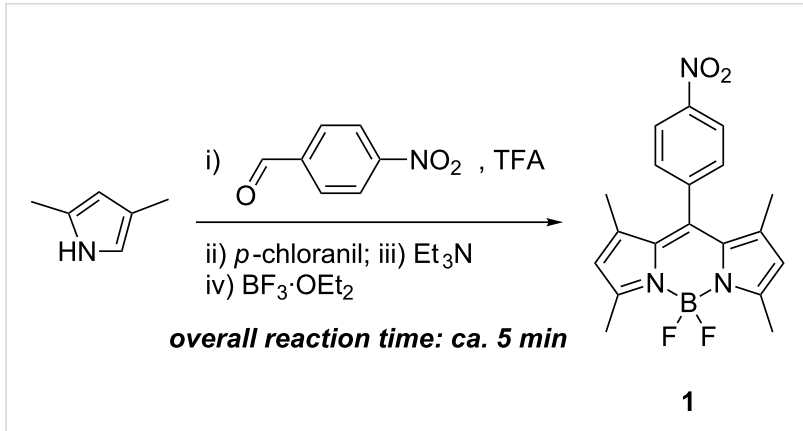

Scheme 2: Expeditious synthesis of dye 1.

In view of this positive result (Table 1, entry 1), we attempted to optimize this procedure (Table 1). Specifically, several oxidizing agents were tried, including the typically used DDQ as well as $\mathrm{Ce}\left(\mathrm{NH}_{4}\right)_{2}\left(\mathrm{NO}_{3}\right)_{6}$. However, $p$-chloranil afforded the highest isolated yield (Table 1, entries 1-3). We also found that adding small amounts of $\mathrm{CH}_{2} \mathrm{Cl}_{2}(1-2 \mathrm{~mL})$ prior to the addition of $p$-chloranil allowed for a more efficient grinding to take place.

\begin{tabular}{llll}
\multicolumn{3}{l}{ Table 1: Optimization of reaction conditions for the synthesis of dye 1.} \\
Entry & Oxidant & Base & Yield, \% ${ }^{\mathrm{a}}$ \\
\hline 1 & $p$-chloranil & $\mathrm{Et}_{3} \mathrm{~N}$ & 29 \\
2 & $\mathrm{DDQ}$ & $\mathrm{Et}_{3} \mathrm{~N}$ & 7 \\
3 & $\mathrm{Ce}\left(\mathrm{NH}_{4}\right)_{2}\left(\mathrm{NO}_{3}\right)_{6}$ & $\mathrm{Et}_{3} \mathrm{~N}$ & 0 \\
4 & $\mathrm{Ce}\left(\mathrm{NH}_{4}\right)_{2}\left(\mathrm{NO}_{3}\right)_{6}$ & $\mathrm{DBU}$ & 8 \\
5 & $p$-chloranil & $\mathrm{DBU}$ & $24^{\mathrm{b}}$ \\
6 & $p$-chloranil & $\mathrm{K} 2 \mathrm{CO}$ & 0 \\
7 & $p$-chloranil & $\mathrm{NaOH}$ & 0 \\
\hline
\end{tabular}

alsolated yield, after column chromatography; ${ }^{b}$ yields varied from 8 to $24 \%$.

Next, we examined several different bases for the deprotonation of the dipyrrolium species. Organic bases such as $\mathrm{Et}_{3} \mathrm{~N}$ and DBU (Table 1, entries 1 and 5), proved to be most effective. Although DBU gave comparable results to $\mathrm{Et}_{3} \mathrm{~N}$, variations in yields were observed, likely due to the air-sensitive nature of DBU (Table 1, entry 5). $\mathrm{Et}_{3} \mathrm{~N}$, however, appeared to give reproducible results. In contrast, inorganic bases added as solids $\left(\mathrm{K}_{2} \mathrm{CO}_{3}\right.$ and $\mathrm{NaOH}$, Table 1, entries 6 and 7, respectively) failed to give the desired product. Overall, this essentially solvent-free, 5-minute procedure can be performed using the same reagents as the solution synthesis.

Finally, we also experimented with isolation procedures of the crude reaction mixture and found that diluting the mixture with $\mathrm{CH}_{2} \mathrm{Cl}_{2}$ and subsequently washing the organic layer with satu- 
rated $\mathrm{Na}_{2} \mathrm{CO}_{3}$ solution (to remove the hydroquinone byproduct), then brine, followed by column chromatography on silica gel gave satisfactory results. It is worth pointing out that isolation and purification of BODIPY dyes appeared to be problematic regardless of the synthetic procedure, i.e., under solution (literature accounts) or mechanochemical (current work) conditions. Vigorous shaking should be avoided during the extraction steps as it led to the formation of stable emulsions, which significantly lengthened the isolation process, and also decreased the overall efficiency of the reaction. However, we found that avoiding the extraction step altogether resulted in lower isolated yields of the BODIPY dyes. Also, $\mathrm{CHCl}_{3}$ was found to be a superior solvent for column chromatography as compared to $\mathrm{CH}_{2} \mathrm{Cl}_{2}$.

With the optimized conditions at hand, we prepared several BODIPY dyes by using commercially available aldehydes and either 2,4-dimethylpyrrole or 3-ethyl-2,4-dimethylpyrrole (Table 2) [13]. The reaction appeared to be insensitive to the electronic effects of the aldehyde, as both electron-donating and electron-withdrawing groups were equally tolerated. The yields were found to be reasonably comparable to those reported in literature (Supporting Information File 1, Table S1). Yet, the reaction times are drastically reduced from hours and several days (the latter holds true, for example, for dyes $4,6,7$ ) to just 5 minutes.

\begin{tabular}{|c|c|c|c|}
\hline$\checkmark$ & $\begin{array}{ll}\mathrm{R}^{2} & \text { i) } \mathrm{TFA} \\
\text { ii) } p \text {-chlo } \\
\text { iii) } \mathrm{Et}_{3} \mathrm{~N} \\
\text { iv) } \mathrm{BF}_{3} \cdot \mathrm{C}\end{array}$ & & $\mathrm{R}^{1}$ \\
\hline Dye & $\mathrm{R}^{1}$ & $\mathrm{R}^{2}$ & Yield, \%a \\
\hline 1 & $4-\mathrm{NO}_{2}$ & $\mathrm{H}$ & 29 \\
\hline 2 & $4-\mathrm{OCH}_{3}$ & $\mathrm{H}$ & 15 \\
\hline 3 & $4-\mathrm{CN}$ & $\mathrm{H}$ & 13 \\
\hline 4 & 4-ethynyl & $\mathrm{H}$ & 32 \\
\hline 5 & $3-\mathrm{OH}$ & Et & $10^{b}$ \\
\hline 6 & $4-\mathrm{CF}_{3}$ & Et & 22 \\
\hline 7 & $\mathrm{C}_{6} \mathrm{H}_{4} \mathrm{R}^{1}=4$-pyridyl & Et & 15 \\
\hline
\end{tabular}

alsolated yield, after column chromatography; ${ }^{b} 23 \%$ yield when DBU was used as a base.

Furthermore, we examined whether acid chlorides would be suitable substrates for this procedure (Scheme 3). It appeared that the condensation between pyrroles and acid chlorides produced dyes 8 and 9 in relatively low yields of $21 \%$ and $10 \%$, respectively. It should be pointed out that in the case of dye 9 (and unlike the synthesis of $\mathbf{8}$ ), the condensation step between 2,4-dimethylpyrrole and benzoyl chloride appeared to be sluggish. Specifically, with dye $\mathbf{8}$, after 1 minute of grinding the pyrrole was consumed as judged by TLC. However, with dye $\mathbf{9}$, a considerable amount of pyrrole remained (extending the grinding time to 5 minutes did not improve the efficiency of this step, as noted by TLC), which could have been the reason for the low yield of the dye 9. Low yields might have been expected due to the significantly more moisture-sensitive nature of the acid chlorides as compared to the aldehydes. Conventional procedures, which utilize solvents and are performed under inert atmosphere for extended periods of time, afford BODIPY dyes in 30-50\% yields [13,14]. Similar to the aldehyde-based synthesis of BODIPY dyes (Table 2), substituting $\mathrm{Et}_{3} \mathrm{~N}$ with DBU led to inferior results: yields of 7\% and 5\% for dyes $\mathbf{8}$ and $\mathbf{9}$, respectively, were obtained.

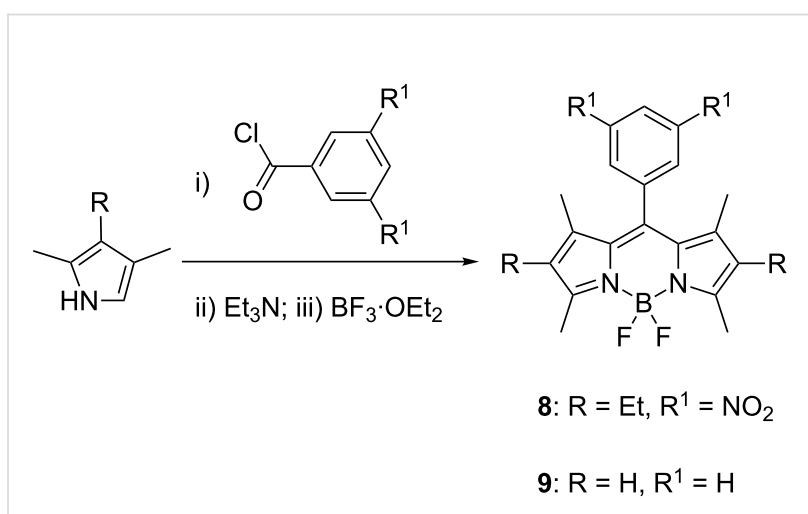

Scheme 3: 5-minute synthesis of dyes 8 and $\mathbf{9}$

In addition, we explored the synthesis of BODIPY dye 10, which does not have a substituent at the meso-position (Scheme 4), using triethyl orthoformate as the aldehyde component. Similar to all other cases, the literature synthesis of this BODIPY dye was performed in solution and required several hours [15]. The synthesis could be accomplished under solventfree conditions within 5 minutes, using the same reagents, in

$$
\text { ii) } \mathrm{Et}_{3} \mathrm{~N} \text {; iii) } \mathrm{BF}_{3} \cdot \mathrm{OEt}_{2}
$$

10 
$29 \%$ yield. An equimolar amount to TFA was used, in order to cleave the acetal to produce the aldehyde, which was condensed with the pyrrole.

\section{Conclusion}

In conclusion, the developed procedure provides a rapid access to BODIPY dyes with reaction times being reduced from several hours or even days to only 5 minutes, while also eliminating large volumes of solvents. The syntheses of BODIPY dyes that used aldehydes as starting materials appeared to be superior to the approach that used acid chlorides. In addition, the unsubstituted BODIPY dye in the meso-position was also prepared via an acid-catalyzed triethyl orthoformate condensation with a pyrrole. Studies on improving the overall efficiency of this process, especially the isolation and purification of the BODIPY dyes, are in progress in our laboratory.

\section{Experimental}

All reagents and solvents were from commercial sources (Sigma-Aldrich or Acros) and were used as received. Column chromatography was performed using silica gel (230-400 mesh) or basic alumina (Brockman I). Fraction collection was monitored by TLC (silica gel $60 \mathrm{~F}_{254}$ ) and the spots were visualized by UV. ${ }^{1} \mathrm{H}$ NMR spectra were recorded on a Varian $(300 \mathrm{MHz})$ spectrometer.

General synthesis for the BODIPY dyes: Aldehyde $(2.5 \mathrm{mmol})$ and pyrrole $(5.0 \mathrm{mmol})$ were mixed with a pestle and mortar. TFA (5 drops) was added via a pipette, while the mixture was ground with the pestle for about 30 seconds. To the resulting paste, $\mathrm{CH}_{2} \mathrm{Cl}_{2}$ or $\mathrm{CHCl}_{3}(2.0 \mathrm{~mL})$ was added (to ensure an easier mixing of all components for the subsequent step; the presence/absence of $\mathrm{CH}_{2} \mathrm{Cl}_{2}$ or $\mathrm{CHCl}_{3}$ had no impact on the reaction time), followed immediately by the addition of p-chloranil $(0.9 \mathrm{~g}, 3.7 \mathrm{mmol})$. The deep red/purple paste was ground for 1 minute, after which TEA $(3.0 \mathrm{~mL}, 21.5 \mathrm{mmol})$ was added via a syringe. The resulting dark brown paste was ground with the pestle for 1 minute. Subsequently, $\mathrm{BF}_{3} \cdot \mathrm{OEt}_{2}(3.0 \mathrm{~mL}$, $23.7 \mathrm{mmol}$ ) was added slowly, dropwise, via a syringe and the mixture was ground for 1-2 minutes until a thick dark red paste was formed. Caution: the addition of $\mathrm{BF}_{3}$. OEt $t_{2}$ results in the formation of white fumes and some bubbling of the solution. Although we have not experienced any safety-related issues, this step (especially when done on a large scale) should be done behind a safety shield to avoid a potential splashing of the mixture. The reaction mixture was dissolved in $\mathrm{CH}_{2} \mathrm{Cl}_{2}$ or $\mathrm{CHCl}_{3}$ $(200 \mathrm{~mL})$, transferred to a separation funnel, and washed with saturated $\mathrm{Na}_{2} \mathrm{CO}_{3}(3 \times 200 \mathrm{~mL})$ followed by brine $(2 \times$ $200 \mathrm{~mL}$ ). The organic solvent was removed in vacuo, and the residue was subjected to column chromatography (silica gel, $\mathrm{CHCl}_{3}$ ) to give the desired product.
Further experimental details (including those for the synthesis of dye 10) and spectroscopic characterization of all BODIPY dyes are given in Supporting Information File 1.

\section{Supporting Information}

\section{Supporting Information File 1}

Experimental procedures and characterization data of prepared BODIPY dyes.

[http://www.beilstein-journals.org/bjoc/content/ supplementary/1860-5397-9-89-S1.pdf]

\section{Acknowledgements}

We would like to thank the National Institute On Aging (Award Number R15AG038977) for financial support of this work. The content is solely the responsibility of the authors and does not necessarily represent the official views of the National Institute On Aging or the National Institutes of Health.

\section{References}

1. Loudet, A.; Burgess, K. Chem. Rev. 2007, 107, 4891-4932. doi:10.1021/cr078381n

2. Ulrich, G.; Ziessel, R.; Harriman, A. Angew. Chem., Int. Ed. 2008, 47, 1184-1201. doi:10.1002/anie.200702070

3. Boens, N.; Leen, V.; Dehaen, W. Chem. Soc. Rev. 2012, 41, 1130-1172. doi:10.1039/c1cs15132k

4. Ono, M.; Watanabe, H.; Kimura, H.; Saji, H. ACS Chem. Neurosci. 2012, 3, 319-324. doi:10.1021/cn3000058

5. Beatty, K. E.; Szychowski, J.; Fisk, J. D.; Tirrell, D. A. ChemBioChem 2011, 12, 2137-2139. doi:10.1002/cbic.201100277

6. Smith, N. W.; Alonso, A.; Brown, C. M.; Dzyuba, S. V. Biochem. Biophys. Res. Commun. 2010, 391, 1455-1458. doi:10.1016/j.bbrc.2009.12.091

7. Ojida, A.; Takshi, T.; Inoue, M.; Fujishima, S.; Lippens, G.; Hamachi, I. J. Am. Chem. Soc. 2009, 131, 6543-6548. doi:10.1021/ja9008369

8. Lin, H.-Y.; Huang, W.-C.; Chen, Y.-C.; Chou, H.-H.; Hsu, C.-Y.; Lin, J. T.; Lin, H.-W. Chem. Commun. 2012, 48, 8913-8915. doi:10.1039/c2cc34286c

9. Iehl, J.; Nierengarten, J.-F.; Harriman, A.; Bura, T.; Ziessel, R. J. Am. Chem. Soc. 2012, 134, 988-998. doi:10.1021/ja206894z

10. Bozdemir, O. A.; Erbas-Cakmak, S.; Ekiz, O. O.; Dana, A.; Akkaya, E. U. Angew. Chem., Int. Ed. 2011, 50, 10907-10912. doi:10.1002/anie.201104846

11. Rousseau, T.; Cravino, A.; Ripaud, E.; Leriche, P.; Rihn, S.; De Nicola, A.; Ziessel, R.; Roncali, J. Chem. Commun. 2010, 46, 5082-5084. doi:10.1039/c0cc01144d

12. Ueno, T.; Urano, Y.; Kojima, H.; Nagano, T. J. Am. Chem. Soc. 2006, 128, 10640-10641. doi:10.1021/ja061972v

13. Ziessel, R.; Bonardi, L.; Retailleau, P.; Ulrich, G. J. Org. Chem. 2006, 71, 3093-3102. doi:10.1021/jo0600151

14. Chen, Y.; Zhao, J.; Guo, H.; Xie, L. J. Org. Chem. 2012, 77, 2192-2206. doi:10.1021/jo202215x

15. Sekiya, M.; Umezawa, K.; Sato, A.; Citterio, D.; Suzuki, K. Chem. Commun. 2009, 3047-3049. doi:10.1039/b903751a 


\section{License and Terms}

This is an Open Access article under the terms of the Creative Commons Attribution License

(http://creativecommons.org/licenses/by/2.0), which permits unrestricted use, distribution, and reproduction in any medium, provided the original work is properly cited.

The license is subject to the Beilstein Journal of Organic Chemistry terms and conditions:

(http://www.beilstein-journals.org/bjoc)

The definitive version of this article is the electronic one which can be found at:

doi:10.3762/bjoc.9.89 